\title{
Aligning public financial management system and free healthcare policies: lessons from a free maternal and child healthcare programme in Nigeria
}

Daniel Chukwuemeka Ogbuabor ${ }^{1,2^{*}}$ (D) and Obinna Emmanuel Onwujekwe 2,3

\begin{abstract}
Background: Relatively little is known about how public financial management (PFM) systems and health financing policies align in low- and middle-income countries. This study assessed the alignment of PFM systems with health financing functions in the free maternal and child healthcare programme (FMCHP) of Enugu State, Nigeria.

Methods: Data were collected through quantitative and qualitative document review, and semi-structured, indepth interview with 16 purposively selected policymakers involved in FMCHP. Data collection and analysis were by guided a framework for assessing alignment of PFM systems and health financing policies. Revenue and expenditure trend analyses were done using descriptive statistics and analysis of variance (ANOVA). Level of significance was set at $\rho<0.05$. Qualitative data were analysed using a framework approach.

Results: The results showed that no more than $50 \%$ of FMCHP fund were collected despite that the promised fund remained unchanged since inception. Revenue generation significantly varied between 2010 and $2016(\rho<0.05)$. Level of pooling was limited by non-compliance with contribution rules, recurrent unauthorised expenditure and absence of expenditure caps. The unauthorised expenditure significantly varied between 2010 and $2016(\rho<0.05)$. Misalignment of budget monitoring and purchasing revealed absence of auditing and delays in provider payment. Refunds to providers significantly varied between 2010 and 2016 ( $\rho$ < 0.05) due to weak Steering Committee, weak vetting team, paper-based claims management and institutional conflicts between Ministry of Health and districtlevel officials.

Conclusions: This study identified important lessons to align PFM systems and FMCHP. A realistic and evidenceinformed budget and enforcement of contribution rules are critical to adequate and sustainable revenue generation. Clarity of roles for various FMCHP committees and use of clear resource allocation strategy would strengthen pooling and fund management. Enforcement of provider payment standards, regular auditing, and a stronger role for the parliament in budgetary processes are warranted.
\end{abstract}

Keywords: Public financial management, Free healthcare, Policy implementation, Nigeria

\footnotetext{
* Correspondence: ogbuabordc@gmail.com

${ }^{1}$ Department of Health Systems and Policy, Sustainable Impact Resource

Agency, University of Nigeria Enugu Campus (UNEC), 22 Ogidi Street, Asata,

Enugu, P.O. Box 15534, Enugu State, Nigeria

${ }^{2}$ Department of Health Administration and Management, University of

Nigeria Enugu Campus, Enugu, Enugu State, Nigeria

Full list of author information is available at the end of the article
}

(C) The Author(s). 2019 Open Access This article is distributed under the terms of the Creative Commons Attribution 4.0 International License (http://creativecommons.org/licenses/by/4.0/), which permits unrestricted use, distribution, and reproduction in any medium, provided you give appropriate credit to the original author(s) and the source, provide a link to the Creative Commons license, and indicate if changes were made. 


\section{Background}

In 2007, Enugu State launched the free maternal and child healthcare programme (FMCHP) to improve financial protection and equity in the use of maternal and child health $(\mathrm{MCH})$ services in publicly-owned health facilities that usually charges user fees [1]. Financial constraints significantly limited access to $\mathrm{MCH}$ services in Nigeria $[2,3]$. Hence, free care policy implies that users do not pay for essential $\mathrm{MCH}$ services and drugs, when available, at point of service delivery. The programme is tax-funded through monthly state and local governments' (SLG) contributions. The FMCHP is governed by a Steering Committee (SC), responsible for oversight, fund management and primary purchasing, and housed within the policy development and planning directorate (PDPD) of the Ministry of Health (MOH). A State Implementation Committee (SIC), housed within the State Health Board (SHB), monitors district-level implementation of FMCHP and serves as financial intermediary between the $\mathrm{SC}$ and service providers.

The flow of funds from FMCHP fund to providers has been fully described in a previous paper [4]. In a nutshell, healthcare providers are paid fees for each patient who received free services based on approved fee schedule. Healthcare providers duly record all transactions and submit monthly claims to the SIC for vetting. Vetted claims are approved by the SC. The SC transfers funds to the SIC to pay providers their approved claims. Whereas healthcare providers receive $70 \%$ of the cost of services, the balance of $30 \%$ is used to defray administrative costs. The FMCHP funds, as all public funds, is subject to Enugu state's public financial management systems and rules including budgeting, financial instructions, financial reporting and auditing.

Public financial management (PFM), described as institutions, policies and processes governing the use of public funds, influence how health financing policies contribute to universal health coverage (UHC) [5-8]. Countries that has made significant progress towards UHC relied on a dominant share of public funds to finance health [9]. Functional PFM systems would ensure that funds meant for health financing policies are adequate and predictable, equitably and efficiently used, better accounted for [5-8]. In contrast, when PFM systems and health financing policies are misaligned, UHC schemes may not be prioritized in the budget, resource allocation might be unpredictable and fund management ineffective and inefficient. Such weak PFM systems may result in ineffective implementation of health financing policies in support of UHC due to significant resource leakages and misuse of public funds [5-8].

Evidence of (mis) alignment of PFM and health financing policies in low and middle-income countries are growing. Funding for UHC schemes in China, Thailand and Eastern European Countries increased and were predictable [10-12], which contrasts evidence of insufficient budgetary allocations and underfunding from Ghana, Nicaragua and India [13-15] and unchanging annual government spending on free care policy in Senegal [16]. State governments defaulted from payment of their contributions to UHC schemes in Nigeria and Mexico [17-19]. Whereas fixed annual budget and cap on provider payment controlled costs Thailand's universal coverage scheme (UCS) [20], non-adherence to spending caps in Mexico's Seguro Popular (SP) resulted in use of funds for unauthorised purposes, high public spending on drugs and contracting unauthorised personnel [19, 21]. Nevertheless, misuse of funds in Mexico's SP necessitated the Ministry of Finance to keep resources out of local treasuries and instead, pay providers directly from resources in federal treasury [21].

The experiences of Mexico confirm that institutional conflicts in fund management, significant delays in transfer of funds from state to healthcare providers, limited financial information disclosure and high administrative cost result from misalignment of PFM systems and health purchasing $[17,19,21]$. Conversely, a low administrative cost was found in Thailand's UCS because the scheme has no revenueraising responsibility and underinvests in administrative functions [22]. In Vietnam, budgets based on historical expenditure of the preceding year resulted in lower fund allocation to providers than their actual healthcare expenditure [23]. In Thailand, hospital directors misallocated resources meant for contracted units of primary care [24]. Lack of administrative and service utilisation data constrained monitoring of free healthcare policies in India and Nigeria $[15,18]$, which contrasts experiences of robust health management information system in Thailand's UCS [20].

The FMCHP policy envisaged that adherence to the public budgeting processes, contribution rules and state financial instructions would ensure predictable SLG budget transfers, transparent financial management and optimal use of FMCHP funds. However, evidence of inadequate funding of the FMCHP and weak commitment of Local Government Councils; declining number of health facilities reimbursed for free $\mathrm{MCH}$ services; and users continuing to pay for notionally free $\mathrm{MCH}$ services indicate that PFM systems and health financing functions in FMCHP are misaligned in Enugu State [25-27]. This paper explores these misalignments and provides evidence of how PFM can be better aligned with FMCHP objectives. Such insights can be used by health policymakers, public budget officials, health providers and development partners to ensure efficient and effective use of public funds to finance free healthcare policies in Nigeria and similar low-resource settings.

\section{Methods}

\section{Conceptual framework}

The study was guided by Cashin and colleagues' framework for assessing alignment of public financial management (PFM) and health financing policies [28]. The 
framework integrates health financing functions and health sector financial management into the budget cycle (Fig. 1). The budget cycle has three stages: budget formulation, budget execution and budget monitoring. Budget formulation aligns with revenue raising in health financing and involves determining resource allocation to FMCHP. Budget execution aligns with pooling of FMCHP funds and involves transfer of approved funds to, and fund management at the $\mathrm{MOH}$. Budget monitoring involves making payments to healthcare providers for free services delivered (purchasing) and ensuring compliance with purchasing rules and accountability of purchasing agencies. This framework was deemed appropriate because it addresses the specific PFM requirements of the health sector and provides functional approach for investigating how PFM and FMCHP could be better aligned to contribute to universal health coverage [28].

\section{Study setting}

The study was conducted in Enugu State, Southeast Nigeria. Enugu State consists of seventeen (17) Local Government Areas (LGAs). The LGAs are delineated into 7 health districts and 68 local health authorities. Between 2008 and 2016, Enugu State population increased by about $28.7 \%$ at $3.2 \%$ growth rate of 2006 census estimate [29]. Children under 5 years and women of childbearing age (WCBA) constitute about $17 \%$ and $45 \%$ of the population respectively [30]. From 2008 to 2013, the proportion of currently pregnant women rose from $7.6 \%$ to $8.4 \%$; the total fertility rate increased from 4.4 to 4.8 ; the proportion of women who are delivered in public health facility increased from $21.4 \%$ to $36.5 \%$; and under-five mortality rate declined from 153 per 1000 livebirths to 131 per 1000 livebirths [30]. Publicly owned health facilities in each district health include a district hospital, cottage hospitals and primary health facilities. There is also a state teaching hospital in the capital city of Enugu.

\section{Research design}

The study adopted a mixed methods design. The quantitative component consists of secondary analysis of financial and administrative data. The qualitative component included document review and in-depth, semistructured interviews. Mixed methods was used because it would sufficiently capture the complexity of implementation processes and the findings could be triangulated [31].

\section{Study population and sampling strategy}

The target population for in-depth interviews were policymakers involved in FMCHP implementation at the state and district levels. We purposively selected state-level policymakers $(n=12)$ from the SC and SIC of the FMCHP and district-level policymakers $(n=4)$ because of their position, involvement in administration of FMCHP and willingness to participate in the study. To facilitate selection of district-level policymakers, we divided the seven health districts into two contrasting clusters of wellperforming and less-well-performing districts using provider payment data and randomly selected one district from each cluster $[4,25]$. Two policymakers were selected from each of the two districts.

\section{Data collection}

Quantitative data were abstracted from administrative and financial records collected from the $\mathrm{MOH}, \mathrm{SHB}$, Enugu State Teaching Hospital and State budget using an abstraction form. The abstraction form included data on SLG budget transfers to FMCHP fund, transfer from the FMCHP fund to SHB's FMCHP account, other

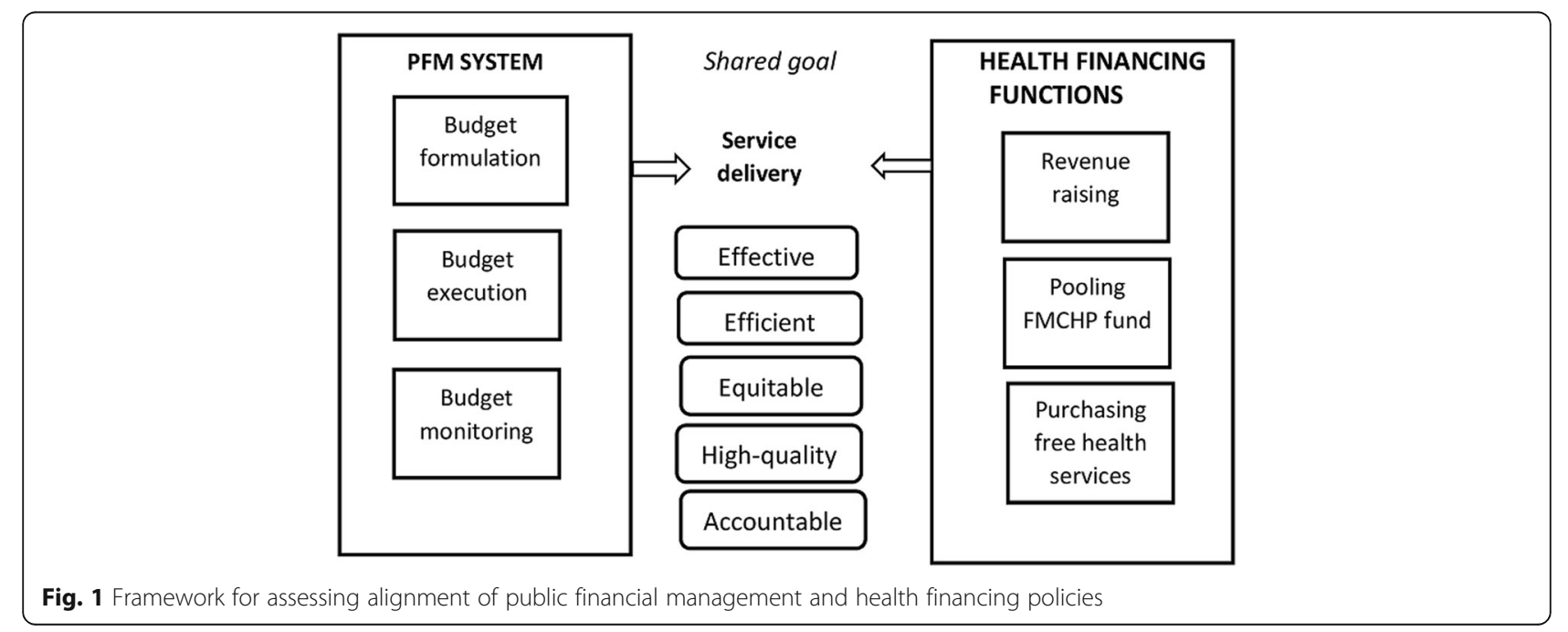


expenditure made from the FMCHP pool, payments to health facilities and central medical stores from SIC, vetted provider claims and audit report.

Qualitative data were extracted from policy documents, programme reports, Hansard and memoranda on FMCHP collected from the $\mathrm{MOH}$ and Enugu State House of Assembly. About 27 documents, purposively selected because they informed the research questions of this study, were reviewed (Additional file 1). The documents were identified in consultation with key $\mathrm{MOH}$ officials and clerk of the House Committee on Health.

We interviewed 16 policymakers using in-depth, semistructured interview guide as a part of large assessment of governance of the FMCHP [25]. The interview guide included questions for assessing FMCHP budget formulation, release of funds to $\mathrm{MOH}$, flow of funds from FMCHP fund to healthcare providers and monitoring of financial management rules. The participants were identified using government officials as gatekeepers. Interviews held in their offices, were conducted in English and lasted about one and half hours. The interviews were audiotaped, transcribed verbatim and the transcripts sent back to participants for validation.

\section{Data analysis}

\section{Quantitative component}

We conducted financial trend analysis of revenue collection, pooling and purchasing. Descriptive statistics used included percentages and graphs. Analysis of variance (ANOVA) was used to measure statistical significance of mean differences in proportion of variables (population of target beneficiaries, revenue raised, pool size, unauthorised expenditure, paid claims and unpaid claims) at $\rho<0.05$. Unauthorised expenditure in this study means spending from the FMCHP funds that are beyond the scope of FMCHP guidelines. Data were analysed using Statistical Package for Social Sciences (SPSS) version 20 (IBM, New York, USA).

\section{Qualitative component}

The interview data were imported into NVivo software (version 11, QSR International Pty Ltd., Victoria, Australia) and analysed using a framework approach [32]. Deductive and inductive coding strategies were used by two independent coders to fit data into categories and inconsistencies resolved by consensus. The main themes were deduced from the conceptual framework of the study. Inductive codes reflected sources of misalignments between PFM and health financing functions and were generated by reading the transcripts and assigning codes to emergent themes.

\section{Ethical consideration}

The study was approved by the Health Research Ethics Committee of the University of Nigeria Teaching Hospital
Enugu, Nigeria. Written, informed consent was obtained from all participants for both participation and audiorecording of interviews.

\section{Results}

Quantitative component

Budget formulation and revenue raising for FMCHP

FMCHP revenue generation significantly varied between 2010 and $2016(\rho<0.05)$. Figure 2 shows that no more than $50 \%$ of the promised revenue (200 million naira per annum) were generated (averaging $41.29 \%$ ) per annum, whereas the population of target beneficiaries significantly increased $(\rho<0.05)$ between 2010 and 2016 .

\section{Budget execution and pooling of FMCHP fund}

An average of $63 \%$ of annual pool size was spent between 2010 and 2016 ranging from $20 \%$ to $90 \%$. The proportion of annual unauthorized expenditure significantly rose from $1 \%$ in 2011 to $79 \%$ in 2014 and declined to $35 \%$ in $2016(\rho<0.05)$ but remained higher than authorized expenditures between 2013 and 2016 (Fig. 3). The average unauthorized expenditure was $34 \%$ per annum.

\section{Budget monitoring and purchasing in FMCHP}

The proportion of the annual pool size used to pay providers significantly varied between 2010 and $2016(\rho<0.05)$ (Fig. 4). Of the 17 reimbursement exercises, about $44 \%$ took a gap of 1 to 3 months, 31\% took 4 to 6 months and 25\% between 7 and 15 months. Most reimbursements included several unpaid claims for the preceding 2 to 3 years. Refunds to the state teaching hospital significantly declined from 2010 to $2016(\rho<0.05)$ and from 2011, is inversely related to unpaid claims (Fig. 5). The unpaid claims significantly increased from 2012 to $2016(\rho<0.05)$.

The administrative cost significantly rose from about $4 \%$ in 2013 to about $19 \%$ in $2016(\rho<0.05)$. Drug costs constitute bulk of FMCHP expenses but significantly declined from about $86 \%$ in 2013 to about 38\% in 2016 $(\rho<0.05)$. The cost of services significantly increased from about $10 \%$ in 2013 to about $43 \%$ in $2016(\rho<0.05)$.

\section{Qualitative component}

Table 1 shows the key themes and sub-themes that characterise the misalignment of PFM system and health financing functions in FMCHP.

\section{Budget formulation and revenue raising for FMCHP}

Document review (DR) showed that FMCHP funding remained at 2008 cost estimate (DR3); the revenue raised were unpredictable, less than the promised fund and always in arears (DR3, DR4, DR6, DR15). In 2009, State Economic Planning Commission (SEPC) set new rules for direct deduction of SLGs' contribution by Joint Accounts and Allocation Committee (DR14, DR15). That notwithstanding, 

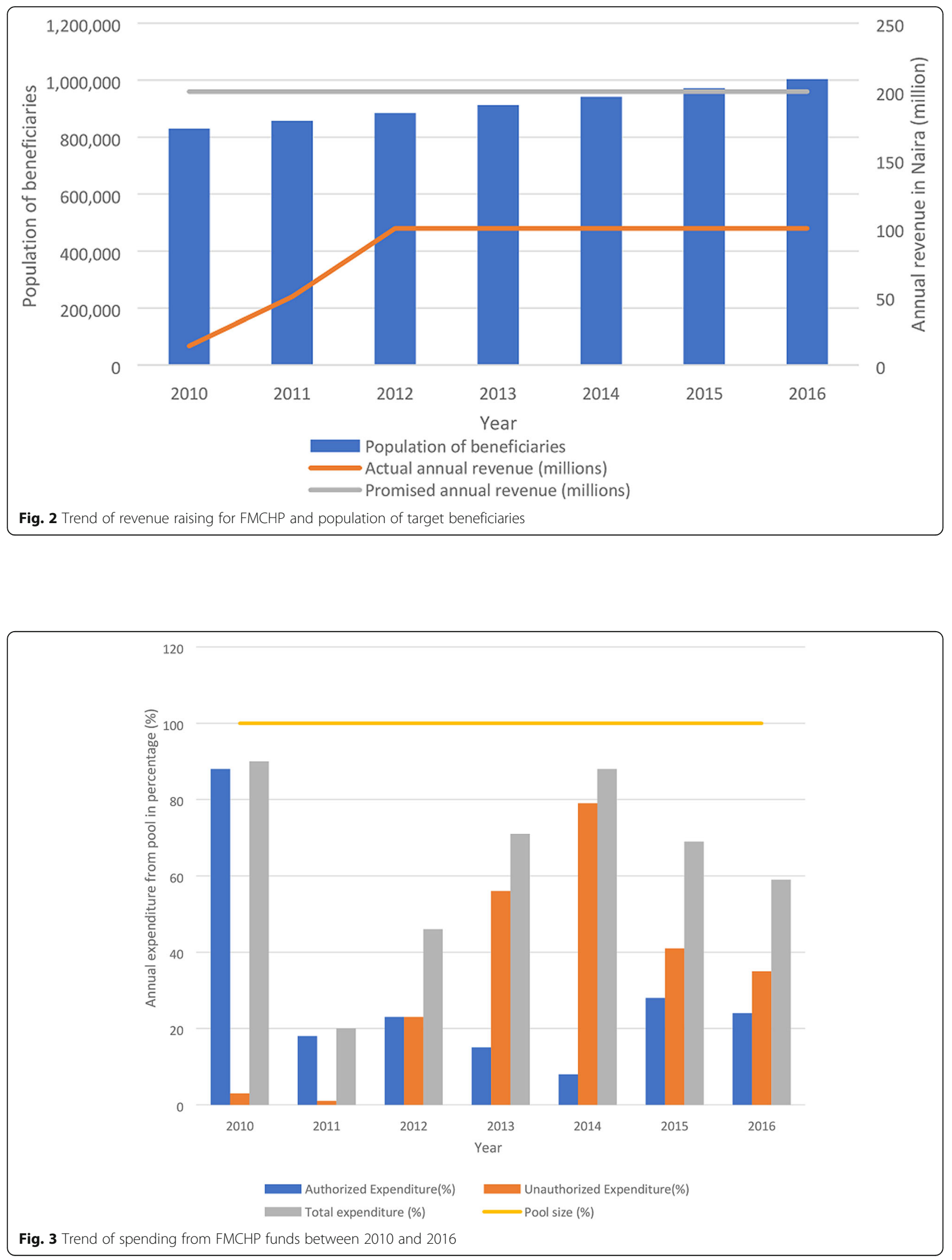


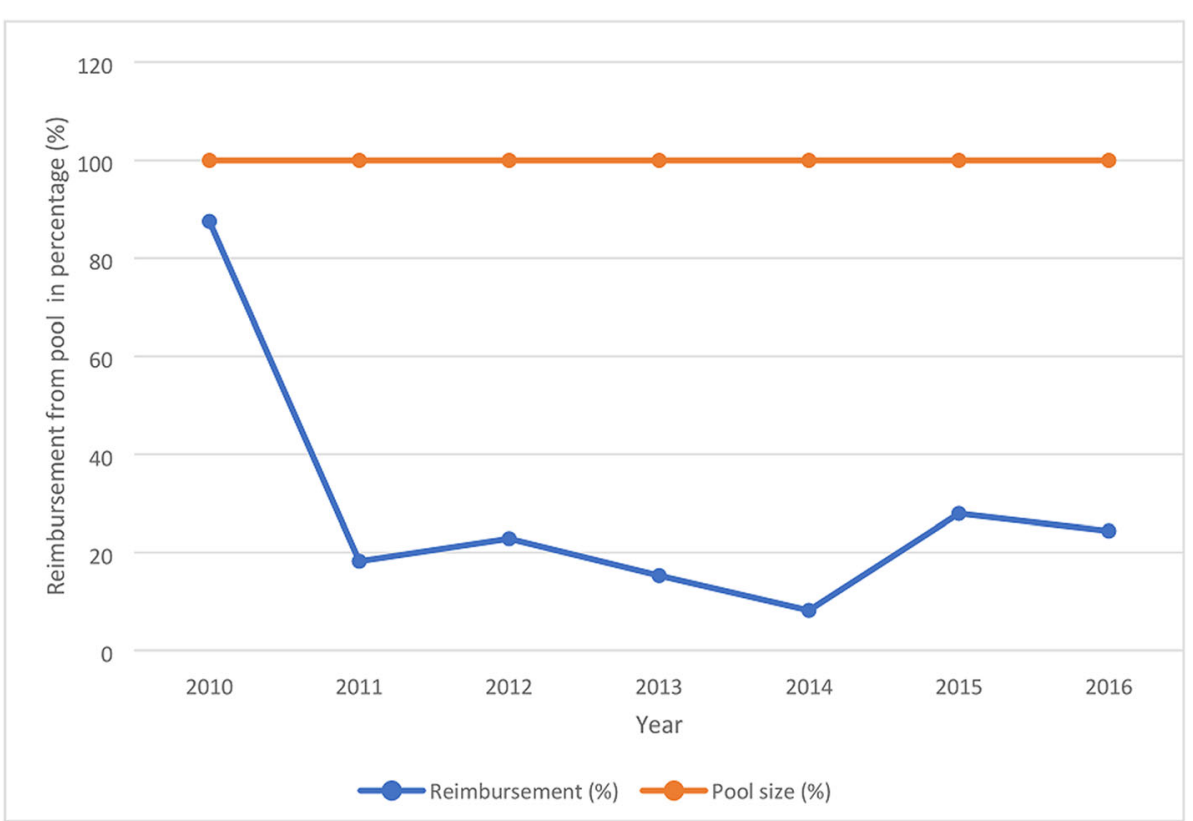

Fig. 4 Proportion of annual pool size spent on payment of healthcare providers

only Local Governments' contributions were deducted and transferred to FMCHP fund (DR14, DR15).

Most policymakers stated that annual budget for FMCHP were historical. Yet compliance with the contribution rule was weak; and the parliament lacked power to alter the budget estimates. Since 2010, only LGs contributed to the FMCHP fund, while "the state government has not actually leaved up to its own responsibilities of making regular contributions" (policymaker 3). Few policymakers indicated that funding ceiling remained unchanged since inception. As one policymaker observed, "Free MCH budget should be reviewed every financial year - either upwards or downwards - but it had remained the same all through which does not look scientific or realistic" (policymaker 10).

\section{Budget execution and pooling of FMCHP fund}

Review of documents indicated that rules for spending FMCHP funds covered services, drugs, laboratory

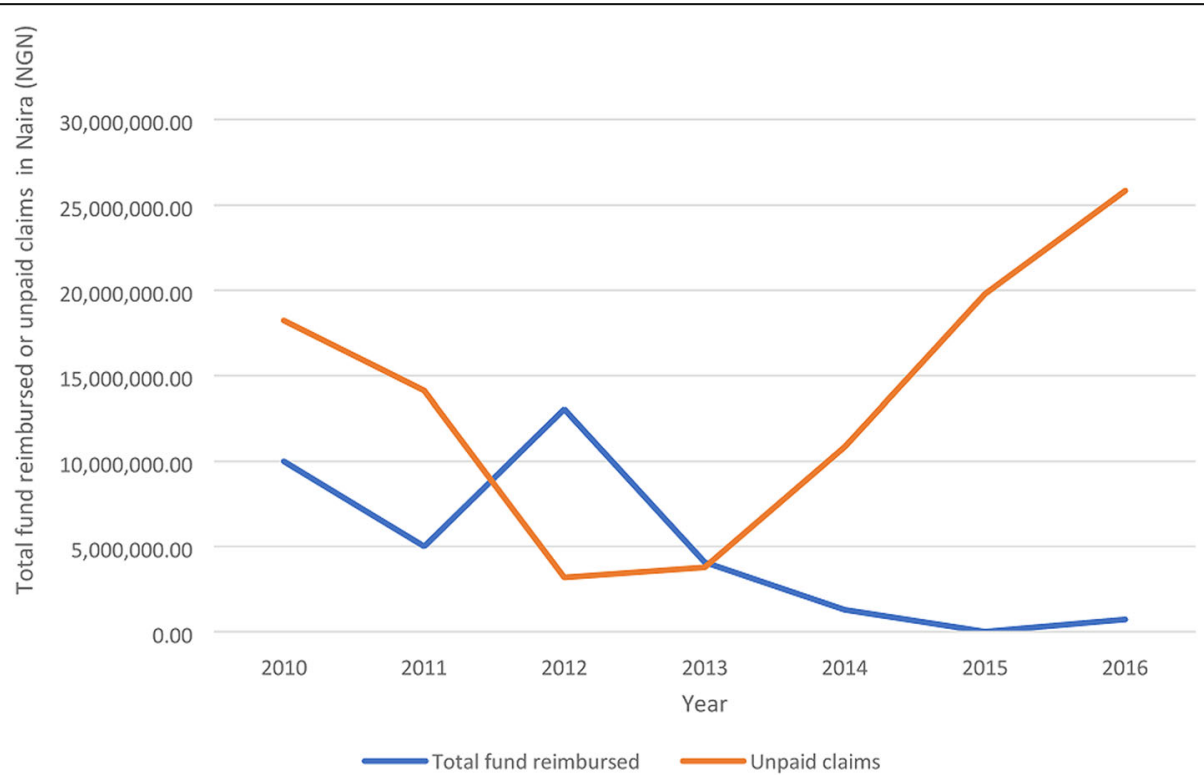

Fig. 5 Trend of annual reimbursement and cumulative unpaid claims in ESUTH 
Table 1 Misalignment of PFM and health financing functions in FMCHP in Enugu State

\begin{tabular}{|c|c|c|c|}
\hline PFM system & Health financing functions & Themes & Sub-themes \\
\hline \multirow[t]{2}{*}{ Budget formulation } & \multirow[t]{2}{*}{ Revenue raising } & \multirow[t]{2}{*}{ Level of funding } & $\begin{array}{l}\text { Weak budgeting with promised funding remaining } \\
\text { static since inception }\end{array}$ \\
\hline & & & Weak enforcement of revised contribution rule \\
\hline \multirow[t]{4}{*}{ Budget execution } & \multirow[t]{4}{*}{ Pooling and fund management } & Level of pooling & $\begin{array}{l}\text { Only Local Government sustained contribution to } \\
\text { FMCHP fund }\end{array}$ \\
\hline & & \multirow[t]{3}{*}{ Level of administrative efficiency } & Weak Steering Committee \\
\hline & & & No spending cap in the FMCHP guidelines \\
\hline & & & High unauthorised expenditure from FMCHP fund \\
\hline \multirow[t]{8}{*}{ Budget monitoring } & \multirow[t]{8}{*}{ Purchasing } & \multirow[t]{2}{*}{ Payment of providers } & Delayed payment of providers \\
\hline & & & Fraction of claims paid to some providers \\
\hline & & \multirow[t]{2}{*}{ Level of administrative efficiency } & Non-remittance of administrative costs to LHAs \\
\hline & & & Over-reporting of attendance by providers (gaming) \\
\hline & & \multirow[t]{4}{*}{ Transparency } & Unclear reimbursement process \\
\hline & & & Lack of financial information disclosure \\
\hline & & & No regular auditing of FMCHP account \\
\hline & & & $\begin{array}{l}\text { Resistance to financial monitoring committee from } \\
\text { SIC officials }\end{array}$ \\
\hline
\end{tabular}

services, vetting of facility claims and mobilisation and advocacy activities (DR1, DR5). Nonetheless, there are no spending caps for resource allocation in the guidelines. FMCHP funds were used to procure 11 vehicles in 2014 (DR14) and fund some activities of the $\mathrm{MOH}$ beyond the scope of FMCHP (DR 22). Yet, we found only one FMCHP audit report (DR22).

Most policymakers said that procedures for spending FMCHP fund are not adhered to. They reported that "Steering Committee met only twice" (policymaker 1) in 7 years and approvals of disbursement from FMCHP fund were done by Commissioner responsible for health. "There were commissioners who delayed approval of reimbursement of providers even when there were lots of funds in the FMCHP account" (policymaker 6). Yet, FMCHP funds were used to finance other health activities which are not authorized by FMCHP guidelines. "When we received certain approvals from the State Governor without cash-backing, we normally took money from the FMCHP fund to finance them" (policymaker 4). The parliamentary committee on health monitors ministerial spending from FMCHP fund, but its role was limited to exposing inefficiencies.

\section{Budget monitoring and purchasing in FMCHP}

Review of documents indicated that at the inception of FMCHP, the SIC paid health facilities through their local health authorities (LHAs), but since 2010, providers were paid directly due to leakages at the LHAs (DR14, DR15). Funds accruing to LHAs to defray administrative cost were not remitted between 2010 and 2015 (DR23). Payment of providers are often late or never done; and most providers are unclear about the claim process (DR3). Some facilities are paid fractions of their claims (DR2). Payment uncertainties resulted in stock-outs of commodities and resumption of user fees in some facilities (DR2, DR10, DR14, DR17, DR19).

Most policymakers identified weak organizational capacity of the SC as obstacle to effective health purchasing. They indicated that SC rarely met, which constrained timely and predictable payment of providers. Approvals for payment of providers were done by the Commissioner responsible for health. Consequently, reimbursement "timelines stipulated in the free care programme guidelines were not met and took more than six months after vetting" (policymaker 2).

Most state-level policymakers explained that there were leakages in funds when LHA secretaries served as financial intermediaries for paying providers: "we discovered that the LHA secretaries were keeping back part of the moneys. So that is why all the facilities were directed to open account" (policymaker 1). District-level policymakers observed that "since state-level policymakers bypassed LHA Secretaries in the reimbursement process, LHA Secretaries became aloof" (policymaker 14) to provider accounting and financial reporting requirements.

Most policymakers observed that reimbursement processes are paper-based and not integrated into state health management information system. Claim forms that were not properly completed were kept aside while figures on mutilated pages of claims form were deducted from total claims before recommending vetted claims to $\mathrm{SC}$ for payment. Few policymakers observed that vetting team conducted quality assurance visits to "verify that 
expenditure claimed in the reimbursement forms corresponded with facility records" (policymaker 8). Sometimes, service data were inconsistent with providers' claims, which is described as data "konjaring", that is over-reporting attendance to increase claims (policymaker 10).

Most policymakers revealed that FMCHP financial information were not publicly disclosed and that the SIC was limited to "writing and issuance of approved reimbursement cheques to health facilities" (policymaker 10). Policymakers also stated that paying providers directly for service charges and through the central medical store for drugs, and existence of financial monitoring committee (FMC) enabled the SIC to comply with purchasing rules. Few policymakers observed that establishment of FMC resulted in conflictual relationship between the PDPD and SHB. "The financial monitoring committee instructed that the Board should never issue cheque to any facility without reporting to the committee. The Board disregarded the directive" (policymaker 8).

\section{Discussion}

The findings showed that financing of FMCHP was insufficient and unpredictable. Consistent with experiences in Senegal [16], the level of promised funds remained unchanged since inception despite increases in population of target beneficiaries and changes in the unit cost of services and drugs due to rising inflation rates [33]. Changes in target population and increase in inflation rates imply underfunding of the scheme even if government transferred fully the existing budget commitment to the programme. Inflation rate affects fiscal policy behaviour in Nigeria [33], and may explain the weak compliance with contribution rules by SLG. Besides evidence of state governments' defaulting in their contributions to UHC schemes in Nigeria and Mexico [17-19], other studies also found poor government commitment to funding UHC schemes consistent with findings of this study [15, 19]. Conversely, Thailand's UCS budget increased substantially between 2002 and 2011 and is timely transferred to the scheme [10, 34]. In comparing Thailand's UCS to Nigeria's FMCHP, increased funding of UCS was due to increased annual fiscal capacities and evidence-informed negotiation of higher capitation rates [22]. Aligning PFM systems and revenue raising to support FMCHP would entail a shift from historical budgeting to formulating a realistic and evidence-informed annual budget for FMCHP, stronger role for the parliament and citizens, and strengthening enforcement of the contribution rules to guarantee appropriate and timely state budget transfer.

The study revealed that absence of clear resource allocation strategy, high unauthorised expenditure from the pool, and weak accountability between SC and SIC constrained efficient pooling and fund management. Lack of spending caps in FMCHP contrasts experiences in Mexico's Seguro Popular, where resource allocation rule stipulates spending caps for human resources, pharmaceuticals and preventive activities [19, 21]. However, experiences in Mexico indicate that resource allocation rules would not necessarily translate to adherence to negotiated expenditure targets as implementers incurred huge unauthorised expenses $[17,19]$. Similarly, this study confirms the Mexico's experiences of use of funds for free care policy for unauthorised activities. The balance of power within the SC seem to have favoured the $\mathrm{MOH}$ to usurp the pooling and fund management function of the SC but resulted in huge unauthorised expenses from FMCHP funds and limited financial information disclosure. In addition, weak accounting and financial reporting from the SIC resulted in institutional conflict between the $\mathrm{MOH}$ and the SHB. The $\mathrm{MOH}$ set the FMC to ensure administrative efficiency in fund management and strengthen the logical link between pooling and purchasing. To better align PFM and pooling and fund management, there is a need for clarity of roles and responsibilities for various FMCHP committees, disclosure of financial information to various stakeholders, clear resource allocation strategy and stronger parliamentary oversight of FMCHP fund.

The study further revealed that misalignment of PFM systems and purchasing is characterised by weak budget evaluation and delay in reimbursing providers for free services. Although financial monitoring committee existed, its activities merely focused on compliance with financial procedures but not how equitably or efficiently funds are used. Similarly, the oversight role of parliamentary committee on health was limited to exposing non-compliance with PFM rules. It is imperative to audit FMCHP fund by an independent agency and examine how effectively and efficiently FMCHP funds have been used to achieve its policy objectives [8].

Provider payment delays arise from delay in accounting and financial reporting by providers, delay in vetting of provider claims and delay in approving and transfer of approved claims to providers. Similar delays in transfer of funds from the state to healthcare providers was found in Mexico [17]. Four factors seem to be influencing the delay in provider payment in this study. The first factor is institutional conflict between LHA secretaries and the MOH. At inception, LHA Secretaries served as financial intermediary between the SIC and providers and had substantial discretion in financial resource allocation to service providers. After 5 years of implementation (in 2012), the MOH commenced transfer of service charges directly to service providers due to allegations of misappropriation of funds by LHA secretaries similar to misallocation of resources to contracted 
units of primary care by hospital directors in Thailand's UCS [24]. Consequently, the LHA Secretaries lost interest in monitoring and supervising the accounting and financial reporting by providers.

The second factor was weak vetting team. Delay in vetting of claims resulted from an initial lack of budgetary support for vetting team, incessant transfer of vetting team members, absence of incentives for the vetting team, weak quality assurance system, weak information and communication technology (ICT) support, and centralization of vetting of claims. Since the revised FMCHP policy in 2013 has provided for use of FMCHP funds to cover administrative costs of vetting claims, a meaningful change would be decentralization of vetting to health districts and linking district vetting offices to central coordinating vetting unit at State Health Board using functional ICT infrastructure.

The third factor is that the FMCHP claims' management is paper-based process and has not been integrated into health management information system (HMIS). This study's finding contrasts experiences in Thailand where evidence of utilization informs the capitation rates (20), but similar to experiences in India and Nigeria where lack of administrative and service utilization data constrained monitoring of free healthcare policies $[15,18]$. Limited ICT infrastructure constrained accounting and financial reporting by providers, vetting of claims and transfer of funds to providers. Although HMIS is not an intrinsic part of provider payment system, it shapes the claims reporting and billing system [35].

The fourth factor is weakness of the SC. Approval of vetted claims is assigned to $\mathrm{SC}$ but in practice, Commissioner responsible for health approves disbursements from FMCHP fund. Thus, weak organizational capacity of SC constrained effectiveness and efficiency of purchasing because approvals depended on (un) willingness of the commissioner to approve funds. As we have argued elsewhere [4], making the purchasing agency an autonomous entity, consistent enforcement of provider payment standards and use of ICT aligned with HMIS to manage provider payment would realign PFM systems and purchasing objectives of the FMCHP.

The study has explored the misalignments between PFM systems and free healthcare policies through a detailed analysis the free maternal and child healthcare policy of Enugu state, south-east, Nigeria. The study has generated useful insights about how public budgeting rules, processes and practices influence free healthcare policies in resource-constrained settings, and the triangulation of quantitative and qualitative findings increases the validity of our conclusion that PFM plays key roles in the effectiveness of free healthcare policies. Evidence from this study may be limited by poor availability and accessibility of financial and administrative records of FMCHP. As an example, outstanding claims of district providers could not be analysed due to lack of data. However, the study leveraged on the first authors' insider-researcher position to obtain timely, the financial records that informed the data reported in this paper.

\section{Conclusion}

This study identified important lessons to align public financial management systems and free healthcare policies in Nigeria and similar settings. A shift from historical budgeting to a realistic and evidence-informed budget and enforcement of contribution rules would ensure sufficient and sustainable revenue generation for FMCHP. Clarity of roles and responsibilities for various FMCHP committees, disclosure of financial information to the various stakeholders, use of clear resource allocation strategy and adherence to fund management rules would strengthen pooling and fund management. Balancing revenue and expenditure, regular auditing, enforcement of provider payment standards and use of ICT aligned with HMIS to manage provider payment would guarantee timely payment of providers. A stronger role for the parliament in budgetary processes in FMCHP is warranted.

\section{Additional file}

Additional file 1: List of documents reviewed (DOCX 14 kb)

\section{Abbreviations}

DR: Document Review; FMCHP: Free maternal and child healthcare programme; LG: Local Government; LGA: Local Government Areas; LHA: Local Health Authority; LHAs: Local Health Authorities; MCH: Maternal and child health; MOH: Ministry of health; PDPD: Policy Development and Planning Directorate; PFM: Public financial management; PHC: Primary health care; REPSS: State Health Protection Regime; SC: Steering Committee; SEPC: State Economic Planning Commission; SHB: State Health Board; SIC: State Implementation Committee; SLG: State and Local Governments; SP: Seguro Popular; UCS: Universal coverage schemes; UHC: Universal health coverage; WCBA: Women of childbearing age

\section{Acknowledgements \\ We are grateful to all participants of the Public Finance and Public Management in Africa Workshop, hosted by Blavatnik School of Government University of Oxford and Ghana Institute of Public Administration, in Accra, Ghana, from 22 to 24 October 2018, for critiquing the manuscript.}

\section{Authors' contributions}

DCO and OEO contributed to conceptualisation of the study. DCO conducted the field work. DCO and OEO analysed the data and contributed to conceptualisation of the manuscript. DCO drafted the manuscript. DCO and OEO contributed to the intellectual content of the article. DCO finalised the article. Both authors read and approved the final manuscript.

\section{Funding}

This work was partially funded by the African Doctoral Dissertation Research Fellowship (ADDRF) (Grant Number: 2014-2016 ADF003) through the African Population and Health Research Centre (APHRC) Nairobi, Kenya, in partnership with International Development Research Centre (IDRC). 


\section{Availability of data and materials}

The datasets generated and/or analysed during the current study are not publicly available but are available from the corresponding author on reasonable request.

\section{Ethics approval and consent to participate}

The study was approved by Health Research Ethics Committee of University of Nigeria Teaching Hospital Enugu, Nigeria (NHREC/05/01/2008BFWA00002458-1-RB00002323). Informed consent was obtained from all participants for both participation and audio-recording of interviews.

\section{Consent for publication}

All the participants were given full information and consented to participate.

\section{Competing interests}

The authors report no conflict of interest.

\section{Author details}

'Department of Health Systems and Policy, Sustainable Impact Resource Agency, University of Nigeria Enugu Campus (UNEC), 22 Ogidi Street, Asata, Enugu, P.O. Box 15534, Enugu State, Nigeria. ${ }^{2}$ Department of Health Administration and Management, University of Nigeria Enugu Campus, Enugu, Enugu State, Nigeria. ${ }^{3}$ Health Policy Research Group, College of Medicine, University of Nigeria Enugu Campus, Enugu, Enugu State, Nigeria.

Received: 3 November 2018 Accepted: 6 June 2019

\section{Published online: 13 June 2019}

\section{References}

1. State Ministry of Health [SMOH]. The guidelines for implementation of free maternal and under-5 child health programme. Enugu, Nigeria: Enugu State Ministry of Health; 2013.

2. Adedini SA, Odimegwu C, Bamiwuye O, Fadeyibi O, De Wet N. Barriers to accessing health care in Nigeria: implications for child survival. Glob Health Action. 2014;7:23499.

3. Akeju DO, Oladapo OT, Vidler M, Akinmade AA, Sawchuck D, Qureshi R, et al. Determinants of health care seeking behaviour during pregnancy in Ogun state. Nigeria Reprod Health. 2016;13(1):32.

4. Ogbuabor DC, Onwujekwe OE. Scaling-up strategic purchasing: analysis of health system governance imperatives for strategic purchasing in a free maternal and child healthcare programme in Enugu state, Nigeria. BMC Health Serv Res. 2018;18:245.

5. Rajan D, Barroy H, Stenberg K. Budgeting for health. In: Schmets G, Rajan D, Kadandale S, editors. Strategizing national health in the 21st century: a handbook. Geneva: World Health Organisation; 2016.

6. Barroy H, Musango L, Hsu J, Van de Maele N. Public financing for health in Africa: from Abuja to the SDGs. Geneva: World Health Organisation; 2016.

7. Goryakin Y, Revill P, Mirelman A, Sweeney R, Ochalek J, Suhrcke M. Public financial management and health service delivery: a literature review. London, UK: Overseas Development Institute; 2017.

8. Piatti-Fünfkirchen M, Schneider P. From stumbling block to enabler: the role of public financial management in health service delivery in Tanzania and Zambia. Health Syst Reform. 2018:4(4):336-45.

9. Mcintyre D, Meheus F, Røttingen JA. What level of domestic government health expenditure should we aspire to for universal health coverage? Health Econ Policy Law. 2017;12(2):125-37.

10. Damrongplasit K, Melnick G. Funding, coverage and access under Thailand's universal health insurance program: an update after ten years. Appl Health Econ Hea. 2015:13(2):157-66.

11. Li C, Hou Y, Sun M, Lu J, Wang Y, Li X, et al. An evaluation of China's new rural co-operative medical system: achievements and inadequacies. BMC Public Health. 2015;15:1079

12. Mathauer I, Theisling M, Mathivet B, Vilcu I. State budget transfers to health insurance funds: extending universal health coverage in low- and middleincome countries of the WHO European region. Int J Equity Health. 2016;15:57.

13. Mathauer I, Cavagnero E, Vivas G, Carrin G. Health financing challenges and institutional options to move towards universal coverage in Nicaragua. Geneva: World Health Organisation; 2010

14. Witter S, Garshong B, Ridde V. An exploratory study of the policy process and early implementation of the free NHIS coverage for pregnant women in Ghana. Int J Equity Health. 2013;12(16):1-11.
15. Nandi A, Holtzman EP, Malani A, Laxminarayan R. The need for better evidence to evaluate the health \& economic benefits of India's Rashtriya Swasthya Bima Yojana. Indian J Med Res. 2015;142(4):383.

16. Witter S, Dieng T, Mbengue D, Moreira I, De Brouwere V. The national free delivery and caesarean policy in Senegal: evaluating process and outcome. Health Policy Plann. 2010;25(5):384-92.

17. Nigenda G, González-Robledo LM, Juárez-Ramírez C, Adam T. Understanding the dynamics of the Seguro popular de Salud policy implementation in Mexico from a complex adaptive systems perspective. Implement Sci. 2016;11(1):68.

18. Onwujekwe O, Obi F, Uzochukwu B. Assessment of the NHIS-MDG free maternal and child health program and the prospects of reactivation/scaleup using the basic health care provision fund in Nigeria. Enugu, Nigeria: Health Policy Research Group, University of Nigeria.; September, 2016. [Research Summary].

19. Nigenda G, Wirtz VJ, González-Robledo LM, Reich MR. Evaluating the implementation of Mexico's health reform: the case ofSeguro popular. Health Syst Reform. 2015;1(3):217-28.

20. Tangcharoensathien V, Limwattananon S, Patcharanarumol W, Thammatacharee J, Jongudomsuk P, Sirilak S. Achieving universal health coverage goals in Thailand: the vital role of strategic purchasing. Health Policy Plann. 2015;30(9):1152-61.

21. OECD. OECD review of health systems: Mexico 2016. Paris: OECD Publishing; 2016.

22. Jongudomsuk $P$, Srithamrongsawat S, Patcharanarumol W, Limwattananon S, Pannarunothai S, Vapatanavong P. The kingdom of Thailand health system review 2015. Manila, Philippines: World Health Organisation, regional Office for the Western Pacific; 2016

23. Tien TV. A health financing review of Vietnam with a focus on social health insurance: bottlenecks in institutional design and organisation practice of health financing and options to accelerate progress towards universal coverage. Geneva: World Health Organisation; 2011.

24. Hughes D, Leethongdee S, Osiri S. Using economic levers to change behaviour: the case of Thailand's universal coverage health care reforms Soc Sci Med. 2010;70(3):447-54

25. Ogbuabor D. Achieving universal health coverage: governance analysis of the free maternal and child healthcare programme in Enugu state, south-East Nigeria. [PhD thesis]. In: Enugu Nigeria: University of Nigeria Enugu campus; 2017.

26. Okeibunor JC, Onyeneho NG, Okonofua FE. Policy and programs for reducing maternal mortality in Enugu state. Nigeria African Journal of Reprod Health. 2010;14(3):19-30.

27. Uzochukwu B, Okwuosa C, Ezeoke O, Onwujekwe O. Free maternal and child healt services in Enugu state, south-east, Nigeria: experiences of the community and health care providers. Int J Med Health Sci Res. 2015;2(9):158-70.

28. Cashin C, Bloom D, Sparkes S, Barroy H, Kutzin J, O'Dougherty S. Aligning public financial management and health financing: sustaining progress toward universal health coverage. Geneva: World Health Organisation; 2017.

29. National Bureau of Statistics [NBS]. 2006 Population Census. Abuja, Nigeria: Federal Government of Nigeria; 2007.

30. National Population Commission [NPC]. Nigeria 2013 Demographic and Health Survey. Abuja, Nigeria: National Population Commission; 2014

31. Creswell JW, Plano-Clark VL. Designing and conducting mixed methods research. Thousand Oaks, California: Sage Publications; 2011.

32. Braun V, Clarke V. Successful qualitative research: a practical guide for beginners. Thousand Oaks, CA: Sage Publications; 2013.

33. Ologbenla P. Determinants of fiscal policy behaviour in Nigeria Invest Manag Financ Innov. 2019;16(2):1-13.

34. Tangcharoensathien $V$, Pitayarangsarit S, Patcharanarumol W, Prakongsai $P$, Sumalee $H$, Tosanguan J, et al. Promoting universal financial protection: how the Thai universal coverage scheme was designed to ensure equity. Health Res Policy Syst. 2013;11(1):25.

35. Cashin C. Assessing health provider payment systems: a practical guide for countries working toward universal health coverage. Washington, DC: Joint Learning Network for Universal Health Coverage; 2015.

\section{Publisher's Note}

Springer Nature remains neutral with regard to jurisdictional claims in published maps and institutional affiliations. 